\title{
O DIREITO DO INDÍGENA À PERÍCIA ANTROPOLÓGICA E A POSSIBILIDADE DE EXERCER A DEMOCRACIA POR MEIO DE UMA IDEIA LEGISLATIVA
}

\author{
INDIGENOUS RIGHT TO ANTHROPOLOGICAL REPORT AND THE \\ POSSIBILITY OF EXERCISING DEMOCRACY THROUGH A LEGISLATIVE \\ IDEA
}

\author{
Victor Melo Fabrício da Silva ${ }^{\mathrm{I}}$ \\ Mônica Nazaré Picanço Dias ${ }^{\mathrm{II}}$
}

\begin{abstract}
${ }^{\mathrm{I}}$ Universidade Federal do Amazonas, Manaus, AM, Brasil. Mestrando em Direito. E-mail: victormelofabricio@ hotmail.com
\end{abstract}

\footnotetext{
II Universidade Federal do Amazonas, Manaus, AM, Brasil. Doutora em
} Direito.E-mail: monicapdias@hotmail. com

DOI: http://dx.doi.org/10.20912/rdc.v15i37.214

Recebido em: 11.02.2020

Aceito em: 29.07.2020
Resumo: $O$ objetivo do presente artigo é trazer para a comunidade acadêmica a possibilidade de exercer diretamente a democracia por meio de uma ideia legislativa apresentada junto ao Senado, com a finalidade de alterar o art. 56 do Estatuto do Índio para tornar obrigatória a realização de Perícia Antropológica nos processos judiciais que envolvam indígenas, demonstrando os instrumentos utilizados e as dificuldades encontradas. Utilizando-se de pesquisa exploratória bibliográfica e documental de natureza aplicada, associada ao estudo do caso concreto ora apresentado, por meio do método indutivo de caráter qualitativo e mídias sociais para divulgação da ideia legislativa, permitiu-se, por um lado, demonstrar a importância do reconhecimento dos direitos dos povos indígenas e, por outro, corroborar a dificuldade da implementação desses direitos em nosso País, além da falta de comprometimento de alguns operadores do direito e de parcela da sociedade brasileira com a temática indígena.

Palavras-chave: Direitos Indígenas. Iniciativa democrática. Perícia Antropológica.

Abstract: The purpose of this article is to bring the possibility to the academic community of directly exercising democracy through a legislative idea presented to the Federal Senate, aiming at change the art. 56 of the Indigenous Statute for make it mandatory the implementation of anthropological reports in judicial proceedings involving indigenous people, demonstrating the instruments used and the difficulties encountered. Using applied exploratory bibliographic and documentary research, associated with the study of the concrete case presented, through the qualitative inductive method and using social media to disseminate the legislative idea, it was allowed, on the one hand, to demonstrate the importance of the indigenous peoples rights recognition and, on the other hand, corroborate the difficulty of 
implementing these rights in our country, in addition to the lack of commitment by some law operators and part of Brazilian society with the indigenous theme.

Keywords: Indigenous rights. Democratic initiative. Anthropological report.

\section{Introduçáo}

O presente artigo aborda uma iniciativa democrática consistente na alteraçáo do art. 56 do Estatuto do Índio ${ }^{1}$, com vistas a tornar obrigatória a realização de perícia antropológica nos processos judiciais que envolvam indígenas. Essa ideia legislativa tem sua origem no ambiente acadêmico da Universidade Federal do Amazonas, local onde se "respira" o contexto amazônico e, por consequência, as questóes indígenas da atualidade, por ser o Amazonas o Estado da Federação com maior número de indivíduos que integram esses povos.

Nesse sentido, ao trazer à lume a referida iniciativa, procura-se abordar a problemática dos direitos das minorias em nosso País, subsumindo-os, por ora, no modo como as autoridades estatais omitem e se omitem quando o assunto é o reconhecimento da condição de indígena - e seus consectários - nos processos a que esses povos são submetidos, especialmente os de viés criminal.

Eis, portanto, o objetivo do presente estudo: trazer para a comunidade acadêmica a possibilidade de uma iniciativa democrática brasileira, apresentando as dificuldades encontradas no que se refere à luta pelos direitos dos povos indígenas em nosso País, os quais, apesar de previstos em nossa Carta Magna, em instrumentos internacionais firmados pelo Brasil e em leis infraconstitucionais, prosseguem historicamente negados ou relegados a um segundo plano.

Para atingir esse objetivo, vale-se de pesquisa exploratória bibliográfica e documental de natureza aplicada associada ao estudo do caso concreto que ora se apresenta, à luz da legislação, autores e pesquisadores que tratam da temática indígena, juntamente com o emprego das mídias sociais - facebook, whatsapp e youtube - para divulgação da ideia legislativa, empregando-se o método indutivo com caráter qualitativo, durante os meses de setembro de 2019 a janeiro de $2020^{2}$.

1 BRASIL. Lei nº 6.001, de 19 de dezembro de 1973. Estatuto do Índio. Planalto. Disponível em: http://www. planalto.gov.br/ccivil_03/Leis/L6001.htm. Acesso em 2 nov. 2019.

2 QUEIROZ, Rafael Mafei Rabelo; FEFERBAUM, Marina (Coord.). Metodologia da pesquisa em direito: técnicas e abordagens para elaboração de monografias, dissertaçóes e teses. 2. ed. São Paulo: Saraiva, 2019. 


\section{Ideia legislativa: uma iniciativa democrática}

Inicialmente, convém trazer à baila do que trata a presente iniciativa democrática, para posteriormente levantar-se o cerne da ideia legislativa ora proposta referente à alteração legal que se pretende no Estatuto do Índio, além de trazer como se originou a iniciativa em apreço e as dificuldades encontradas nesse percurso.

No Capítulo $2^{3}$ de sua obra, Menezes ${ }^{4}$ traz as formas típicas e atípicas de engajamento democrático mais utilizadas no Brasil, destacando-se dentre as primeiras a participação em eleiçóes gerais, os projetos de lei de iniciativa popular e a participação em referendos e plebiscitos e, entre as segundas, caracterizadas pelo autor como "novos canais de acessibilidade cidadá no Brasil”, destacam-se a iniciativa popular de leis na Câmara dos Deputados, por intermédio das "Sugestóes Legislativas", e a iniciativa popular de leis no Senado Federal, por intermédio das “Ideias Legislativas". É desta última forma de engajamento democrático que trata o presente Artigo.

Assim, verifica-se que apesar de o Senado Federal não ser o órgão legislativo responsável por iniciar as demandas legislativas de iniciativa popular, sua Comissão de Direitos Humanos e Legislação Participativa é responsável, dentre outras atribuições, por receber e analisar sugestóes legislativas oriundas da sociedade civil organizada, nos termos do Regimento Interno daquela Casa 5 .

Ao par dessa possibilidade, como ressalta o Professor ${ }^{6}$, a citada Comissáo analisa sugestôes oriundas da plataforma on line "Ideias Legislativas", localizada no portal e-cidadania do site do Senado ${ }^{7}$, desde que tais sugestóes tenham recebido o número igual ou superior a 20.000 (vinte mil) apoios virtuais. Logo, verifica-se que esse canal virtual disponibilizado pelo Senado Federal possibilita a um único cidadão propor uma ideia legislativa que poderá (ou não) se tornar/alterar uma lei, desde que consiga o apoio de ao menos 20 mil outras pessoas.

Diante desses ensinamentos e vislumbrando a existência de grandes óbices no Brasil em concretizar os direitos dos povos indígenas - conforme percebido já no início dos estudos junto à Universidade Federal do Amazonas -, passa-se a imaginar o que poderia ser feito, a curto prazo e dentro de um contexto normativo, para a concretização de direitos indígenas, optando-se por focar em seu viés jurisdicional ${ }^{8}$.

3 O Capítulo 2 tem como título: "Acessibilidade cidadã: a utilização de canais institucionais típicos e atípicos de engajamento democrático".

4 MENEZES, Rafael da Silva. Democracia Brasileira: discurso, possibilidades e responsabilidades na Constituição Federal de 1988. Rio de Janeiro: Lumen Juris, 2019, p. 127.

5 Ibidem, p. 156

6 Ibidem, p. 157.

7 Disponível em: https://www12.senado.leg.br/ecidadania/principalideia.

8 O viés jurisdicional foi escolhido por envolver o tema do Projeto de Dissertação junto ao Curso de Mestrado da UFAM, relacionado à Jurisdição Indígena. 
A partir daí é que surge a "ideia de uma ideia legislativa” no sentido de buscar inserir dispositivo no Estatuto do Índio com a finalidade de tornar obrigatória a realização da Perícia Antropológica - a ser abordada no tópico seguinte - nos processos a que indígenas forem submetidos, a despeito dos Projetos de Lei (PL) que correm nas Casas do Congresso Nacional há anos, mas que infelizmente não conseguem tornar-se leis. $\mathrm{Ou}$ seja, imaginou-se que tentar alterar o Estatuto do Índio atualmente em vigor seria mais célere do que a aprovação dos projetos que correm em ambas as casas do Congresso.

Quanto a essas iniciativas, ressalta-se que nas últimas décadas, além de projetos de lei para alterar o Estatuto do Índio - com objetivos diversos -, propostas de emenda constitucional e outros projetos esparsos para regular temas relacionados aos indígenas e suas Terras, em ambas as casas do Congresso Nacional, são dignos de destaque os Projetos de Lei no 2.057/19919 (Câmara dos Deputados) e no 169/2016 ${ }^{10}$ (Senado Federal), os quais buscam dispor sobre uma nova codificação indígena, em substituição ao Estatuto atual.

O primeiro, proposto em 29 de outubro de 1991 pelos Deputados Aloizio Mercadante, Fábio Feldmann, José Carlos Sabóia, Nelson Jobim e Sidney de Miguel, dispondo sobre o "Estatuto das Sociedades Indígenas", traz a obrigatoriedade da perícia antropológica em seu artigo 90, in verbis:

Nos processos criminais contra índios, o juiz ordenará a realizaçáo de perícia antropológica, que determinará o grau de consciência da ilicitude do ato praticado, para efeito da aplicação do Artigo 21 do Código Penal.

Parágrafo único: As penas de detenção e reclusão serão cumpridas em regime aberto, preferencialmente na aldeia em que vive o índio. (grifei)

Já o segundo, proposto pelo Senador Telmário Mota em 19 de abril de 2016, traz a mesma obrigatoriedade em seu artigo 151, veja-se:

Art. 151. Condenado o índio por infração penal cometida contra não-índio, a pena poderá ser atenuada, e na aplicação o juiz considerará as peculiaridades culturais do réu.

$\$ 1^{\circ}$ Nos processos criminais contra índios, o juiz ordenará a realizaçáo de perícia antropológica, a fim de determinar o grau de consciência da ilicitude do ato praticado, para efeito da aplicação do disposto no art. 21 do Código Penal.

$\$ 2^{\circ}$ As penas de reclusão e de detenção serão cumpridas, sempre que possível, em regime aberto, no local de funcionamento da unidade administrativa do órgáo indigenista federal mais próxima do domicílio do condenado. (grifei)

Entretanto, conforme as páginas de acompanhamento de ambas as Casas legislativas na internet, os citados PL encontram-se estacionados, sendo seus últimos movimentos

9 BRASIL. Câmara dos Deputados. Projeto de Lei 2.057, de 23 de outubro de 1991. Câmara. Disponível em: https://www.camara.leg.br/proposicoesWeb/fichadetramitacao?idProposicao=17569. Acesso em 20 nov. 2019.

10 BRASIL. Senado. Projeto de Lei no 169, de 19 de abril de 2016. Senado. Disponível em: https://www25. senado.leg.br/web/atividade/materias/-/materia/125563. Acesso em 20 nov. 2019. 
na Câmara e no Senado, respectivamente, em 20/06/2012 e 14/02/2019. De qualquer forma, à luz dos dispositivos anteriormente transcritos, percebe-se a importância do tema e da premente necessidade em se positivar no âmbito do processo o dever de realizar o exame.

\section{A perícia antropológica: finalidade e previsão legal}

O instituto processual da Perícia tem sua previsão normativa em diversos diplomas, sendo mais usuais os conceitos trazidos pelos Códigos de Processo Civil e Processo Penal, com destaque, respectivamente, dos seus artigos 464 e seguintes, e 159 e $160^{11}{ }^{12}$.

Nesse sentido, conforme $\mathrm{Maia}^{13}$, a perícia corresponde à pesquisa, exame ou verificação acerca da verdade ou da realidade de certos fatos, quando sua prova depender de conhecimento técnico ou científico, feita por profissional universitário com conhecimento na área de especialidade da matéria, sendo destinada a assistir o magistrado no esclarecimento desses fatos no processo.

Por sua vez, a Perícia Antropológica é o exame realizado quando a complexidade de determinados fatos sociais exigirem, para serem compreendidos, um conhecimento especializado do saber antropológico com vistas a demonstrar aspectos do mundo social do grupo pesquisado, como sua cosmovisão, crenças, costumes, hábitos, práticas, valores, interações sociais e ambientais etc. ${ }^{14}$.

Dessa forma, pode-se conceituar a Perícia Antropológica como o exame realizado por Antropólogo, com a finalidade de dar assistência ao destinatário do Laudo produzido para se chegar à verdade ou realidade de fatos envolvendo grupos étnicos, a exemplo de indígenas, quilombolas, ciganos, populaçóes tradicionais etc.

No caso específico dos povos indígenas, o Laudo Antropológico produzido pelo perito irá revelar, dentre outros aspectos, os usos, costumes e tradiçóes, bem como os modos de ser, de viver, de se expressar etc., desses povos. A previsão legal de sua realização pode ser encontrada especialmente na Convenção no 169 da OIT e na Constituição Federal.

Assim, a Convenção no 169 da Organização Internacional do Trabalho (OIT) sobre os Povos Indígenas e Tribais adotada em Genebra, em 27 de junho de 1989, aprovada

11 BRASIL. Lei no 13.105, de 16 de março de 2015. Código de Processo Civil. Planalto. Disponível em: http:// www.planalto.gov.br/ccivil_03/_ato2015-2018/2015/lei/113105.htm. Acesso em 20 nov. 2019.

12 BRASIL. Decreto-lei no 3.689, de 3 de outubro de 1941. Código de Processo Penal. Planalto. Disponível em: http://www.planalto.gov.br/ccivil_03/decreto-lei/del3689compilado.htm. Acesso em: 24 nov. 2019.

13 MAIA, Luciano Mariz. Do papel da perícia antropológica na afirmação dos direitos dos índios. OLIVEIRA, João Pacheco; MURA, Fábio; SILVA, Alexandra Barbosa da. (Orgs.). Laudos Antropológicos em Perspectiva. Brasília: ABA, p. 48-76, 2015, p. 48. Disponível em: http://www.aba.abant.org.br/administrator/product/ files/80_00110705.pdf. Acesso em: 29 dez. 2019.

14 Ibidem, p. 48. 
pelo Decreto Legislativo no $143 / 2002$, e promulgada pelo Decreto no $5.051 / 2004^{15}$, traz, em seus arts. $8^{\circ}, 1 ; 9$ o, 2 e 10, 1, o seguinte:

Artigo $8^{\circ}$

1. Ao aplicar a legislação nacional aos povos interessados deverão ser levados na devida consideração seus costumes ou seu direito consuetudinário.

Artigo 9०

2. As autoridades e os tribunais solicitados para se pronunciarem sobre questóes penais deverão levar em conta os costumes dos povos mencionados a respeito do assunto.

Artigo 10

1. Quando sançôes penais sejam impostas pela legislação geral a membros dos povos mencionados, deverão ser levadas em conta as suas características econômicas, sociais e culturais.

Por sua vez, o art. 231 da Constituição Federal ${ }^{16}$, ao tratar dos povos indígenas, prevê que: "São reconhecidos aos índios sua organizaçáo social, costumes, línguas, crenças e tradiçóes, e os direitos originários sobre as terras que tradicionalmente ocupam, competindo à União demarcá-las, proteger e fazer respeitar todos os seus bens".

À leitura dos dispositivos da Convenção acima transcritos, definitivamente incorporados ao sistema legal brasileiro, combinados com o art. 231 da Carta brasileira, pode-se afirmar não haver dúvidas em caber ao magistrado deferir a realização de perícia antropológica em todo e qualquer processo penal que tenha um índio como acusado ${ }^{17}$.

Isso porque, ao processar o indígena, a utilização da perícia se faz necessária para assegurar os direitos desses povos a um processo justo, respeitando-se sua organização social, costumes, línguas, crenças e tradiçóes, conforme prevê a Carta Magna.

Entretanto, por não haver dispositivo legal expresso prevendo a obrigatoriedade do exame, o Ministério Público de modo geral não o solicita e, de outro vértice, a maioria dos magistrados entende não ser necessária sua realização, tendo como principal argumento o de que as provas constantes dos autos demonstrariam grau de integração do indígena à sociedade que dispensaria a realização do laudo. Porém a questão não é essa: além de direito desses povos, a perícia serve, em suma, para demonstrar ao juízo a realidade dos fatos sob a ótica do índio, independentemente do que se considera certo/ errado ou lícito/ilícito sob a ótica da sociedade nacional.

15 BRASIL. Decreto no 5.051, de 19 de abril de 2004. Promulga a Convenção no 169 da Organização Internacional do Trabalho - OIT sobre Povos Indígenas e Tribais. Planalto. Disponível em: http://www. planalto.gov.br/ccivil_03/_ato2004-2006/2004/decreto/d5051.htm. Acesso em: 2 nov. 2019.

16 BRASIL. Constituição (1988). Constituição da República Federativa do Brasil: promulgada em 5 de outubro de 1988. Planalto. Disponível em: http://www.planalto.gov.br/ccivil_03/constituicao/constituicaocompilado. htm. Acesso em 20 nov. 2019.

17 PONTES, Bruno Cézar Luz. O Índio e a Justiça Criminal Brasileira. Direito Penal e Povos Indígenas. VILARES, L. F. (Coord.). 1ª ed. (ano 2010), 3a impr. Curitiba: Juruá, p. 167-223, 2014, p. 221. 
Além do exposto, há de se ressaltar, ainda, que a não realização da Perícia Antropológica no decorrer do processo pode induzir a uma conclusão errônea de que o índio não é índio, tendo como consequência, em caso de condenação penal, o desrespeito de outros direitos, dentre os quais destacam-se os previstos nos artigos 56 e 57 do Estatuto do Índio, como a atenuação da pena, regime e local de cumprimento da pena e reconhecimento da aplicação de sançóes pelos próprios grupos tribais:

Art. 56. No caso de condenação de índio por infração penal, a pena deverá ser atenuada e na sua aplicação o Juiz atenderá também ao grau de integração do silvícola.

Parágrafo único. As penas de reclusão e de detenção serão cumpridas, se possível, em regime especial de semiliberdade, no local de funcionamento do órgáo federal de assistência aos índios mais próximos da habitação do condenado.

Art. 57. Será tolerada a aplicação, pelos grupos tribais, de acordo com as instituiçóes próprias, de sançôes penais ou disciplinares contra os seus membros, desde que não revistam caráter cruel ou infamante, proibida em qualquer caso a pena de morte.

Isso é corroborado pelos estudos de Baines ${ }^{18}$, em que foram observados o desrespeito e a falta de informação acerca dos direitos devidos aos indígenas presos no Município de Boa Vista (Roraima), negando-lhes sua identidade étnica, com consequentes prejuízos na aplicação e cumprimento das penas e local de seu encarceramento, que terminam em redundar numa dupla discriminação dentro e fora do cárcere (por serem presos e por serem indígenas), além de manter esses indivíduos deslocados de seu lugar dentro das estatísticas carcerárias, falseando dados e mantendo-os em sua invisibilidade legal como sujeitos de direitos diferenciados.

Não à toa, tentando corrigir essas injustiças, o Conselho Nacional de Justiça emitiu a Resolução no 287, de 25 de junho de $2019^{19}$, com a finalidade de "estabelecer procedimentos ao tratamento das pessoas indígenas acusadas, rés, condenadas ou privadas de liberdade", bem como as "diretrizes para assegurar os direitos dessa populaçáo no âmbito criminal do Poder Judiciário" ${ }^{20}$.

Tal resolução trouxe como principais aspectos, no sentido do reconhecimento de direitos dos indígenas, a possibilidade da autodeclaração como indígena, a presença de intérprete em determinados casos, a possibilidade do reconhecimento dos mecanismos próprios de responsabilização da comunidade indígena, a consideração dos direitos relativos ao tratamento penal das mulheres indígenas, o reconhecimento dos direitos $\mathrm{e}$

18 BAINES, Stephen Grant. A situação prisional de indígenas no sistema penitenciário de Boa vista, Roraima. Vivência: Revista de Antropologia (UFRN). Natal, v. 1, n. 46, p. 143-158, 9 mar. 2016, p. 147/153. Disponível em: https://periodicos.ufrn.br/vivencia/article/view/8778/6263. Acesso em: 29 dez. 2019.

19 Com vigência a partir de 30 de setembro de 2019, a citada resolução recebeu para sua execução um Manual com orientaçóes a tribunais e magistrados para seu cumprimento. O Manual está disponível em: https://www.cnj.jus. br/wp-content/uploads/2019/09/Manual-Resolu\%C3\%A7\%C3\%A3o-287-2019-CNJ.pdf.

20 CONSELHO NACIONAL DE JUSTIÇA (CNJ). Resolução no 287, de 25 de junho de 2019. Disponível em: https://atos.cnj.jus.br/files/resolucao_287_25062019_08072019182402.pdf. Acesso em: 9 nov. 2019. 
garantias por ocasião da execução de pena restritiva de liberdade em estabelecimentos penais etc.

Porém, nem tudo são flores. Seu artigo $6^{\circ}$ manteve como faculdade ${ }^{21}$ ao juízo a realização da Perícia, ainda que tenha especificado aspectos importantes de sua elaboração e a possibilidade do reconhecimento dos direitos previstos nos artigos 56 e 57 do Estatuto do Índio:

Art. $6^{\circ}$ Ao receber denúncia ou queixa em desfavor de pessoa indígena, a autoridade judicial poderá determinar, sempre que possível, de ofício ou a requerimento das partes, a realização de perícia antropológica, que fornecerá subsídios para o estabelecimento da responsabilidade da pessoa acusada, e deverá conter, no mínimo:

I - a qualificação, a etnia e a língua falada pela pessoa acusada;

II - as circunstâncias pessoais, culturais, sociais e econômicas da pessoa acusada;

III - os usos, os costumes e as tradiçóes da comunidade indígena a qual se vincula;

IV - o entendimento da comunidade indígena em relação à conduta típica imputada, bem como os mecanismos próprios de julgamento e punição adotados para seus membros; e V - outras informaçôes que julgar pertinentes para a elucidação dos fatos.

Parágrafo único. O laudo pericial será elaborado por antropólogo, cientista social ou outro profissional designado pelo juízo com conhecimento específico na temática. (grifei).

De qualquer forma, caso tal previsão institucional não logre resolver definitivamente a problemática da realização obrigatória da Perícia Antropológica no âmbito judicial (isso só o futuro dirá), é inegável que pode ser considerada um passo relevante para o reconhecimento da importância dos direitos indígenas de modo geral.

\section{Estudo de caso: uma possibilidade de iniciativa democrática}

Iniciando o processo de iniciativa democrática em apreço, em 22 de setembro de 2019 foi acessado o site "e-cidadania"22 do Senado Federal e encaminhada a ideia legislativa com o seguinte texto:

Alteração do art. 56 do Estatuto do Índio para tornar obrigatória a realização de perícia.

21 A Resolução traz em seu art. $6^{\circ}$ uma faculdade ao prever que a autoridade judicial "poderá" determinar a realização da perícia antropológica "sempre que possível, de ofício ou a requerimento das partes...", porém, curiosamente, seu Manual traz isso como dever do magistrado, ao prever que "O laudo antropológico deve ser solicitado de ofício quando a autoridade judicial receber denúncia ou queixa em desfavor de pessoa indígena ou a requerimento das partes, conforme previsão do art. 6 da Resoluçáo CNJ 287/2019".

22 Para inserir uma ideia legislativa, devem-se seguir os seguintes passos: site e-cidadania ideia legislativa enviar ideia entrar (com Facebook, Google ou mediante novo cadastro). Chega-se então à página de Cadastro de ideia legislativa, escolhe-se a Área Temática (administrativo, econômico, jurídico, social etc.) e insere-se o título da ideia legislativa, sua descrição e "mais detalhes", onde se pode explicar melhor a proposição. Os campos possuem limitação de caracteres (90 caracteres para o Título, 300 caracteres para a Descrição e 400 caracteres para "Mais detalhes". 
A ideia visa cumprir o previsto no art. 231 da Constituiçáo Federal c/c o no 1 do art. 10 da Convençâo no 169 da OIT, tornando obrigatória a Perícia Antropológica nos processos a que os indígenas forem submetidos, como medida de legalidade e preservação de direitos desses povos. Insere o $₫ 2^{\circ}$.

Art. $56(\ldots)$

$\$ 1^{\circ}$ As penas de reclusão e de detenção serão cumpridas, se possível, em regime especial de semiliberdade, no local de funcionamento do órgão federal de assistência aos índios mais próximos da habitação do condenado.

$\$ 2^{\circ}$ Nos processos a que o indígena for submetido, deverá obrigatoriamente ser realizada perícia antropológica por profissional nomeado pelo juízo.

Aqui convém destacar que na página de inserção da ideia legislativa há limitação de caracteres, motivo pelo qual optou-se pelo texto acima transcrito, tendo de ser resumido para descrever a ideia legislativa em relação ao texto inicial previsto ${ }^{23}$ :

A seguinte ideia legislativa visa atender ao previsto no caput do art. 231 da Constituição Federal, combinado com o no 1 do art. 10 da Convençáo no 169 da Organizaçáo Internacional do Trabalho para, dessa forma, tornar obrigatória a realizaçáo de Perícia Antropológica em todos os processos a que os indígenas forem submetidos, como medida de legalidade e preservação dos direitos desses povos.

Para tanto, solicita-se a alteração do parágrafo único do art. 56 do Estatuto do Índio em $\S 1^{\circ}$, bem como a inclusão do $\$ 2^{\circ}$ no mesmo dispositivo, nos seguintes termos:

Lei no 6.001, de 19 de dezembro de 1973 (Estatuto do Índio)

$[\ldots]$

Art. 56. No caso de condenação de índio por infração penal, a pena deverá ser atenuada e na sua aplicação o Juiz atenderá também ao grau de integração do silvícola.

$\S 1^{\circ}$ As penas de reclusão e de detenção serão cumpridas, se possível, em regime especial de semiliberdade, no local de funcionamento do órgão federal de assistência aos índios mais próximos da habitação do condenado.

$\S 2^{\circ}$ Nos processos a que o indígena for submetido, deverá obrigatoriamente ser realizada perícia antropológica por profissional nomeado pelo juízo.

A ideia foi então publicada em 24 de setembro de 2019, sendo recebido um e-mail de confirmaçáo do site e-cidadania com link para acesso e a informação de que a ideia ficaria aberta a receber apoio durante quatro meses, período no qual precisaria receber 20 mil apoios para ser formalizada na Comissão de Direitos Humanos e Legislação Participativa (CDH).

A partir daí iniciou-se o trabalho de divulgação da ideia legislativa, utilizando-se inicialmente o perfil pessoal da rede social Facebook e por meio do aplicativo Whatsapp. Para ambas as redes de contatos, foi encaminhado o link da ideia legislativa juntamente com solicitação de apoio e divulgação, num universo que abrange amigos, familiares, colegas de trabalho, colegas de profissão e colegas da Universidade Federal do Amazonas, 
chegando-se a um montante, em ambas as redes, de pelo menos 503 (quinhentas e três) pessoas $^{24}$.

Após repetidas investidas em ambas as redes sociais e tendo-se verificado o baixo número de apoios (apenas 48 apoios até 28 de outubro de 2019), decidiu-se ser mais incisivo, sendo confeccionado um vídeo para divulgação da ideia legislativa para publicação no Youtube, além do seu encaminhamento aos mesmos grupos e contatos individuais originais (no Facebook e no Whatsapp), na tentativa de despertar o interesse pelo tema.

O vídeo foi publicado no Youtube em 31 de outubro de $2019^{25}$, possuindo somente 48 (quarenta e oito) visualizaçóes naquela plataforma até 14 de janeiro de 2020. Seu conteúdo, de exatamente dois minutos de duração, traz figuras (desenhos) de crianças indígenas extraídas da internet, além de dizeres que buscam explicar o que é a Perícia Antropológica e qual sua finalidade e importância, ao som da música Nhaneramoii Karai Poty, ${ }^{26}$ interpretada pelo Coral Infantil de Tribos Guaranis (Álbum Ñande Reko Arandu - Memória Viva Guarani). O objetivo do vídeo, em suma, foi o de esclarecer e convencer os destinatários a apoiarem a iniciativa por tratar-se de um direito dos povos indígenas, possibilitando assim processos mais justos e a preservação dos direitos dessas minorias. Ao final do vídeo, foi disponibilizado um e-mail de contato criado justamente para dúvidas, críticas e sugestôes relativas à presente ideia legislativa: indiotbtemdireitos@gmail.com.

Quanto ao aumento do número de apoios após a publicação do vídeo, ele foi inexpressivo (de 48 para 65 apoios até 14 de janeiro de 2020). Nesse percurso, foram recebidas poucas mensagens de apoio, havendo, em contrapartida, muita indiferença, a qual, somada às críticas recebidas, explica os números inexpressivos do apoio recebido, o que se considera surpreendente tratando-se de um universo no qual ao menos trezentas pessoas possuem nível superior, devendo ser, portanto, mais esclarecidas sob o ponto de vista do reconhecimento dos direitos dos povos indígenas em nosso País.

Diz-se isso em virtude do teor das críticas recebidas, as quais versaram sobre a discordância com aspectos culturais dos indígenas e a ideia de que eles seriam "malandros" e que “já possuem direitos demais”. Dessa forma, a realização de Perícia Antropológica foi vista pelos críticos como um "benefício" e não propriamente um direito.

Essa visão do indígena, por si só, já demonstra que a discriminação contra esses povos ainda persiste enraizada na sociedade nacional, ainda que se diga o contrário, mantendo esses indivíduos marginalizados, invisíveis ao restante da sociedade e ao Estado, incluindo-se neste o Poder Judiciário, cuja missão precípua deveria ser o cumprimento da lei.

24 Contabilizados os "amigos" do Facebook (226) e os grupos e contatos do Whatsapp (316) para os quais foram encaminhadas a ideia e a solicitação de apoio, descontando-se os contatos repetidos em ambas as redes (39).

25 "Projeto de Lei - Laudo Antropológico Indígenas": https://www.youtube.com/watch?v=hU7Lx0T4tsE.

26 Disponível em: https://www.youtube.com/watch?v=MoK_Xb2X6GQ. 
Tais inferências são corroboradas por Souza Filho ${ }^{27}$ ao lecionar que, embora reconhecidos formalmente pela lei, muitas vezes os direitos dos indígenas sáo desconsiderados pelo Poder Judiciário, seja pela estrutural dificuldade de acesso, seja pela deficiência da organização e indisposição ideológica dos magistrados, o que contribui para manter essa odiosa invisibilidade.

Nesse mesmo sentido, Baines ${ }^{28}$ retrata a descaracterização étnica dos indígenas no Estado de Roraima, praticada pelos operadores do Direito em geral (policiais, delegados, procuradores, juízes, secretários estaduais de segurança pública, secretários estaduais de justiça e cidadania etc.), de modo que aqueles que deveriam ser os principais responsáveis por assegurar os direitos desses indivíduos, são os primeiros a violá-los.

Ao par dessas consideraçôes, pode-se afirmar que essa resistência ao reconhecimento dos direitos desses povos também é reflexo do histórico desrespeito aos direitos fundamentais em nosso País, baseado numa cultura jurídica marcada por um inconsciente coletivo eivado de arquétipos de autoridade e interesses egoísticos decorrentes do processo de formação colonial da sociedade brasileira, o que nos mantém distantes do modelo de sociedade fraterna planejado pelo constituinte no preâmbulo de nossa Carta Magna ${ }^{29}$.

Essa dificuldade da sociedade brasileira em desenvolver um sentimento de fraternidade vai ao encontro do lecionado por Menezes $^{30}$, no que se refere ao baixo número de pessoas que se envolve em pretensōes democráticas em nosso País, apesar do quantitativo da populaçáo brasileira e de cidadãos alistados frente aos diversos mecanismos de engajamento democrático atualmente disponibilizados. Assim, o que falta à nossa sociedade, além do respeito e sentimento fraterno em relação ao outro, é o comprometimento com o seu próprio destino e com o destino de seus semelhantes.

\section{Conclusóes}

Antes de concluir, deve-se esclarecer não haver a pretensão de considerar a breve pesquisa ora realizada como uma profunda análise de dados ou um "trabalho de campo", nem necessariamente afirmar como verdade que o objetivo almejado pela ideia legislativa não foi alcançado devido à falta de interesse geral pela temática indígena ou devido à divulgação insuficiente ou deficiente.

27 SOUZA FILHO, Carlos Frederico Marés de. O Renascer dos Povos Indígenas para o Direito. $1^{\text {a }}$ ed. (ano 1998), 9a reimpr. Curitiba: Juruá, 2018, p. 186.

28 Opus citatum, p. 153.

29 JABORANDY, Clara Cardoso Machado. A Fraternidade no Direito Constitucional brasileiro: um instrumento para proteção de direitos fundamentais transindividuais. Tese (Doutorado em Direito) - UFBA. Salvador, 2016, p. 155. Disponível em: https://repositorio.ufba.br/ri/bitstream/ri/20048/1/CLARA\%20CARDOSO\%20 MACHADO\%20JABORANDY.pdf. Acesso em: 29 dez. 2019.

30 Opus citatum, p. 161-162. 
Para tanto seria necessário o emprego de mais tempo e uma metodologia adequada para a busca e análise de dados, o que muito provavelmente também conduziria a uma pesquisa diferente, com foco nas reaçóes e/ou nos resultados da ideia legislativa, diferentemente do objetivo atual.

Assim, o foco deste breve estudo foi o de trazer um pouco das possibilidades presentes numa iniciativa democrática, demonstrando o passo-a-passo de uma de suas formas mais simples e acessíveis pela população em geral: a ideia legislativa. Além disso, aproveitou-se a oportunidade para "sonhar" com a possibilidade de, individualmente, tentar participar do processo legislativo brasileiro, ao mesmo tempo em que se buscava corrigir a ausência da realizaçáo da Perícia Antropológica nos processos penais envolvendo indígenas, por meio da alteração do art. 56 do Estatuto do Índio que poderia torná-la obrigatória.

De qualquer forma, as reações recebidas e a baixa adesão à ideia legislativa dentro do universo de contatos de familiares, amigos, colegas de trabalho, colegas de profissão e colegas de universidade, apresentou um resultado bem aquém do esperado, o que permite sim corroborar a dificuldade da implementação de direitos dos povos indígenas em nosso País, o que é no mínimo preocupante, considerando-se o prazo decorrido desde a promulgaçáo da Constituição (31 anos) e da vigência da Convençáo no 169 da OIT para o Brasil $\left(16\right.$ anos $\left.^{31}\right)$, ainda que sua promulgaçáo tenha ocorrido quase um ano depois ${ }^{32}$.

Além do exposto, de acordo com a pesquisa bibliográfica realizada, considera-se igualmente preocupante a falta de comprometimento dos operadores do direito com os direitos dos povos indígenas, bem como da sociedade brasileira em relação ao seu destino e dos seus semelhantes. Outrossim, em relação aos primeiros, não deve ser discricionário ao magistrado decidir se determina ou não a realização da perícia, já que se entende ser um direito que assiste ao indígena, sendo sua realização, portanto, obrigatória.

Por sua vez, a supracitada Resolução do CNJ, em nossa modesta opinião, ainda deixa margem para essa discricionariedade, o que só seria solucionado definitivamente com a cogência legal de sua realização.

Por fim, apesar da baixa adesão à ideia legislativa proposta, pode-se considerar positiva a oportunidade de aprender mais sobre a democracia brasileira e os direitos dos povos indígenas, além de poder trazer à comunidade acadêmica a importância do reconhecimento dos direitos desses povos.

\section{Referências}

BAINES, Stephen Grant. A situação prisional de indígenas no sistema penitenciário de Boa vista, Roraima. Vivência: Revista de Antropologia, Natal, v. 1, n. 46, p. 143-158, 9 
mar. 2016. Disponível em: https://periodicos.ufrn.br/vivencia/article/view/8778/6263. Acesso em: 29 dez. 2019.

BRASIL. Constituição (1988). Constituição da República Federativa do Brasil: promulgada em 5 de outubro de 1988. Disponível em: http://www.planalto.gov.br/ ccivil_03/constituicao/constituicaocompilado.htm. Acesso em 20 nov. 2019.

BRASIL. Decreto-lei no 3.689, de 3 de outubro de 1941. Código de Processo Penal. Disponível em: http://www.planalto.gov.br/ccivil_03/decreto-lei/del3689compilado. htm. Acesso em: 24 nov. 2019.

BRASIL. Lei $n^{\circ}$ 6.001, de 19 de dezembro de 1973. Estatuto do Índio. Disponível em: http://www.planalto.gov.br/ccivil_03/Leis/L6001.htm. Acesso em 2 nov. 2019.

BRASIL. Lei no 13.105, de 16 de março de 2015. Código de Processo Civil. Disponível em: http://www.planalto.gov.br/ccivil_03/_ato2015-2018/2015/lei/l13105.htm. Acesso em 20 nov. 2019.

BRASIL. Decreto $n^{\circ} 10.088$, de 5 de novembro de 2019. Consolida atos normativos editados pelo Poder Executivo Federal que dispóem sobre a promulgaçáo de convençôes e recomendaçóes da Organização Internacional do Trabalho - OIT ratificadas pela República Federativa do Brasil. Disponível em: http://www.planalto.gov.br/ccivil_03/_ Ato2019-2022/2019/Decreto/D10088.htm\#anexo72. Acesso em: 28 jul. 2020.

BRASIL. Câmara dos Deputados. Projeto de Lei 2.057, de 23 de outubro de 1991. Disponível em: https://www.camara.leg.br/proposicoesWeb/ fichadetramitacao?idProposicao=17569. Acesso em 20 nov. 2019.

BRASIL. Senado. Projeto de Lei no 169, de 19 de abril de 2016. Disponível em: https:// www25.senado.leg.br/web/atividade/materias/-/materia/125563. Acesso em 20 nov. 2019.

CONSELHO NACIONAL DE JUSTIÇA (CNJ). Resolução no 287, de 25 de junho de 2019. Disponível em: https://atos.cnj.jus.br/files/ resolucao_287_25062019_08072019182402.pdf. Acesso em: 9 nov. 2019.

JABORANDY, Clara Cardoso Machado. A fraternidade no Direito Constitucional brasileiro: um instrumento para proteção de direitos fundamentais transindividuais. Tese (Doutorado em Direito) - UFBA. Salvador, 2016. Disponível em: https:// repositorio.ufba.br/ri/bitstream/ri/20048/1/CLARA\%20CARDOSO\%20 MACHADO\%20JABORANDY.pdf. Acesso em: 29 dez. 2019.

MAIA, Luciano Mariz. Do papel da perícia antropológica na afirmaçáo dos direitos dos índios. OLIVEIRA, João Pacheco; MURA, Fábio; SILVA, Alexandra Barbosa da. (Orgs.). Laudos antropológicos em perspectiva. Brasília: ABA, p. 48-76, 2015. Disponível em: http://www.aba.abant.org.br/administrator/product/files/80_00110705.pdf. Acesso em: 29 dez. 2019. 
MENEZES, Rafael da Silva. Democracia brasileira: discurso, possibilidades e responsabilidades na Constituição Federal de 1988. Rio de Janeiro: Lumen Juris, 2019.

PONTES, Bruno Cézar Luz. O índio e a justiça criminal brasileira. In: VILARES, L. F. (Org.). Direito penal e povos indigenas. Curitiba: Juruá, 2014, p. 167-223.

QUEIROZ, Rafael Mafei Rabelo; FEFERBAUM, Marina (Org.). Metodologia da pesquisa em direito: técnicas e abordagens para elaboração de monografias, dissertações e teses. 2. ed. São Paulo: Saraiva, 2019.

SOUZA FILHO, Carlos Frederico Marés de. O renascer dos povos indigenas para o Direito. Curitiba: Juruá, 2018. 